\title{
Nahrungsmittelallergie: Augmentationsfaktor ASS
}

einer Patientin, die auf den Genuß von Bier und ASS hin eine Rhinitis und Konjunktivitis bekam. Auch im Zusammenspiel mit dem Verzehr von Zwiebeln oder von Petersilie konnte Paul eine ASS-Augmentation, manifestiert in Form einer Urtikaria, ver-

\section{Als Auslöser von Intoleranzreaktionen genießt Acetylsalicylsäure (ASS) in der allergologischen Praxis einen zweifelhaften Ruf. Gerade für Patienten mit chronischer Urtikaria hat sie als tabu zu gelten. Offensichtlich vermag ASS jedoch auch allergische Reaktionen auf Nahrungsmittel zu verstärken. Hierzu gibt es mittlerweile mehrere Fallberichte.}

Einen interessanten Fall einer solchen durch Acetylsalicylsäure (ASS) verstärkten Nahrungsmittelallergie stellte Eberhard Paul, Nürnberg, vor. Er berichtete von einer 39jährigen Patientin, die über viele Jahre hinweg mehrmals unter schweren Urtikariaschüben wie auch unter Schockzuständen litt. Akribische Tagebuchaufzeichnungen erg aben: Jedem dieser Ereignisse war der Verzehr eines Rohkostsalates vorausgegangen.

\section{$P$ rovokationstests verlaufen zunächst sehr mild}

Der naheliegende Verdacht einer Nahrung s mittel alle rgie wurde diagnostisch bestätigt. Allerdings verliefen die Provokationstests auch bei größeren Mengen überaus milde: „Es kam nur zu einem leichten Kribbeln an der Mundschleimhaut - nicht einmal zur Urtikaria“, schilderte Paul die zunächst überraschend erscheinenden Ergebnisse.

Nach diesen ersten erfolglosen diagnostischen Bemühungen förderte die eingehendere Anamnese zutage, daß die Patientin bei Kopfschmerz gelegentlich auch ASS einnahm. Zum Te s t auf ASS-vermittelte Intoleranzreaktionen wurde die 39jährige mit diesem Cyclooxygenasehemmer provoziert. „Wir waren ganz erstaunt", so Paul w e i t e r, ,daß auch diesmal die Reaktion ausblieb."

Worin bestand also das auslösende Agens bei der Patientin? Die Antwort erhielt Paul, indem er eine kombinierte Testung mit Sonnenblumenkernen und
ASS vornahm. Prompt kam die Patientin in den Schock bei zugleich dichtstehenden Urticae über den ganzen Körp e r. „Erst die Kombination führte zu den schweren Reaktionen - klarer Fall also einer Allergieaugmentation durch ASS“, resümierte Paul.

Im Nürnberger Klinikum-Nord sind mittlerweile 4 ähnliche Fälle registriert - ,und ich bin sicher, daß diese Zahl noch steigen wird", kommentierte der Dermatologe. Er erwähnte den Fall Histaminintoleranz genannt. währt. merken.

\section{Mechanismus der Augmentation noch nicht ganz sicher}

Der Mechanismus der Augmentation könnte laut Paul so aussehen, daß Ty p I - A 11 e rgien dadurch verstärkt werden, indem ASS die gastrale Resorption des Allergens steigert.,Tierex perimentelle Untersuchungen belegen“, so Paul, „daß ASS die Penetration im Darm fördert.“

Als Schlußfolgerungen aus diesen Beobachtungen resultierte dann auch Pauls Empfehlung: „Bei Nahrungsmitt e 1 a 11 e rgien sollten Sie dem Patienten sagen, daß er bei Schmerzen möglichst keine Acetylsalicylsäure einnehmen soll.“

(ro)

Quelle: Seminar „Urtikaria-Therapie“, unterstützt von Hoechst Marion Roussel im Rahmen der 16. Fortbildungswoche für praktische Dermatologie und Venerologie
München 1998.

\section{Allergie oder Pseudo-Allergie?}

Wie unterscheiden sich Allergie und Pseudo-Allergie? Während eine Allerg i e als spezifische Änderung der Immunitätslage im Sinne einer krankmachenden Überempfindlichkeit verstanden wird, spricht man von einer Pseudo-Allerg i e wenn eine nicht-immunologische Überempfindlichkeit sich mit klinischen Symptomen manifestiert, die allergischen Erkrankungen entsprechen.

Als Auslöser einer pseudo-allergischen Reaktion werden beispielhaft Protamin, Acetylsalicylsäure, Salizylate, Benzoate, Kaliumjodid, Opiate und die

Bezogen auf das klinische Bild der Urtikaria sind pseudo-allergische Reaktionen in 20 bis $80 \%$ der Fälle als ursächlich angeschuldigt worden. In jüngster Zeit wurden Autoantikörper gegen den spezifischen IgE-Rezeptor bei rund einem Drittel der Patienten mit chronisch rezidivierender Urtikaria nachgewiesen und als pathogenetisch bedeutsam angesehen. Neben dem direkten Nachweis der Antikörper ist auch der autologe Serum-Intrakutantest diagnostisch hilfreich.

Bei den histaminbedingten Reaktionsformen müssen Intoxikationen durch histaminreiche Nahrung (z.B. Fischkonserven) von den Intoleranzreaktionen abgegrenzt werden. Letzterem liegt wahrscheinlich eine Enzymstörung im Sinne eines Diaminoxidase-Polymorphismus zugrunde. Zur Abklärung derartiger Reaktionen hat sich eine orale Provokation mit $1,5 \mathrm{mg} \mathrm{Histamin/kg} \mathrm{KG} \mathrm{be-}$ 